\title{
In vivo and in vitro Evaluation of Cytokine Expression Profiles During Middle East
} Respiratory Syndrome Coronavirus (MERS-CoV)
Infection

\section{Ayman Mubarak (ID) \\ Bahauddeen Alrfaei ${ }^{2}$ \\ Abdullah Aljurayyan ${ }^{3}$ \\ Mahfoudh M Alqafil' \\ Mohamed A Farrag' \\ Maaweya E Hamed' \\ Bandar Alosaimi $\mathbb{D}^{4}$ \\ Fahad Almajhdi' \\ Wael Alturaiki ${ }^{5}$}

'Department of Botany and Microbiology, College of Science, King Saud University, Riyadh, Saudi Arabia; ${ }^{2}$ Stem Cells Unit, Department of Cellular Therapy, King Abdullah International Medical Research Center, King Saud Bin Abdulaziz University for Health Science, MNGHA, Riyadh, Saudi Arabia; ${ }^{3}$ Immunology and HLA Department, Pathology and Laboratory Medicine, King Fahad Medical City, Riyadh, Saudi Arabia; ${ }^{4}$ Research Center, King Fahad Medical City, Riyadh, Saudi Arabia; ${ }^{5}$ Department of Medical Laboratory Sciences, College of Applied Medical Sciences, Majmaah University, Majmaah, I 1952, Saudi Arabia
Background: Middle East respiratory syndrome coronavirus (MERS$\mathrm{CoV}$ ) first emerged in the Kingdom of Saudi Arabia, is associated with a high mortality rate. Aim: To determine the effect of MERS-CoV on the immune response in infected patients and investigate cytokine production in the A549 epithelial cell line in response to a recombinant MERS-CoV spike protein (rSP) in the presence or absence of antidipeptidyl peptidase 4 (DPP4) antibody (3 independent experiments). Cytokine levels were measured using a cytokine ELISA array.

Methods: A Bio-Plex multiplex assay and cytokine ELISA were used in our study to measure the cytokine levels.

Results: Comparative analysis of MERS-CoV-infected patients (4 samples) and noninfected healthy controls (HCs) (5 samples) showed that serum levels of the following cytokines and chemokines were significantly higher in MERS-CoV patients than in the HCs $\left({ }^{*} p<0.05\right)$ : interferon (IFN)- $\alpha 2$ (43.4 vs 5.4), IFN- $\beta$ (17.7 vs 6.2), IFN- $\gamma$ (43.4 vs 9.7), interleukin (IL)-8 (13.7 vs 0 ), IL-2 (11.2 vs 3 ), IL-27p28 (57.8 vs 13.8 ), and IL-35 (167.5 vs 87.5 ).

Discussion: Our results revealed that MERS-CoV infection induced a slight increase in IFN levels but triggered a more pronounced increase in expression of the regulatory cytokines IL27 and IL-35. A recombinant version of the full-length MERS-CoV spike protein increased the expression of IL-8 (160 pg/mL), IL-2 (100 pg/mL) and IL-12 (65 pg/mL) in A549 lung epithelial cells compared to that in the unstimulated control cells. The presence of anti-DPP4 antibody did not affect cytokine suppression or induction in A549 cells in vitro but decreased the level of IL-8 from $160 \mathrm{pg} / \mathrm{mL}$ to $65 \mathrm{pg} / \mathrm{mL}$.

Conclusion: MERS-CoV can decrease IFN levels to interfere with the IFN pathway and enhance the production of regulatory cytokines. Inhibition of the increases in IL-27 and IL35 may contribute to halting MERS-CoV in the early stage of infection.

Keywords: MERS-CoV, proinflammatory cytokines, regulatory cytokines, anti-DPP4, IFNs, A549 lung cells

\section{Introduction}

Middle East respiratory syndrome coronavirus (MERS-CoV) belongs to lineage $\mathrm{C}$ of the Betacoronavirus $(\beta \mathrm{CoV})$ genus, the members of which have a single-stranded positive RNA (+ssRNA) genome. MERS-CoV can be transmitted through the respiratory tract and affects epithelial cells of the lung and other immune cells, causing acute
Correspondence: Wael Alturaiki Department of Medical Laboratory Sciences, College of Applied Medical Sciences, Majmaah University, Majmaah, 1 1952, Saudi Arabia

Email w.alturaiki@mu.edu.sa 
respiratory distress syndrome (ARDS). ${ }^{1}$ First identified in two patients suffering from severe acute respiratory disease in Saudi Arabia in late 2012, the virus has since spread globally to approximately 27 countries and infected more than 2200 individuals worldwide with a mortality rate of $35 \%{ }^{2,3}$ The MERS-CoV spike protein interacts with the dipeptidyl peptidase 4 (DPP4)/CD26 receptor as a host entry receptor, which not only facilitates viral entry into target cells but also elicits immunosuppression in infected people. ${ }^{1}$ MERS-CoV is similar to most viruses in that it has developed strategies to attack the immune response, especially the innate immune response.

The expression of interferons (IFNs), a hallmark of the early innate immune response, protects against viral infection. However, coronaviruses can inhibit the secretion of IFNs using different strategies, ${ }^{4}$ including the expression of viral accessory proteins (M, ORF4a, ORF4b, and ORF5), which are potent IFN antagonists. ${ }^{5}$ Doublestranded RNA (dsRNA) recognition in the innate immune response is initiated by a pattern recognition receptor (PRR). The dsRNA is recognized by Toll-like receptor-3 (TLR-3) ${ }^{6}$ and both cytosolic melanoma differentiation-associated protein 5 (MDA-5) and retinoic acid inducible gene-I (RIG-1). ${ }^{7}$ The binding of IFN to these proteins initiates the activation of IFN regulatory factors (IRF4 and IRF7) and subsequent induction of IFN type I (IFN- $\alpha$ and IFN- $\beta$ ). ${ }^{8}$

In this study, we investigated the impact of MERS-CoV infection on the innate immune response (IFNs (IFN- $\alpha$ and IFN- $\beta$ )), Th1 (IL-12 and IFN- $\gamma$ ) and Th2 (IL-10) and Th17 (IL-26) cytokines and regulatory cytokines (IL-27 and IL35)). We also investigated cytokine production in the A549 epithelial cell line in response to a recombinant MERS-CoV protein in the presence or absence of anti-DPP4 antibody. Targeting of the DDP4 receptor did not have a therapeutic effect since it does not regulate the proinflammatory response during infection. Both IL-35 and IL-27 may play a role in the regulation of cytokine production. The suppressive effects of IL-27 and IL-35 may contribute to the halting of MERS-CoV in the early stage of infection.

\section{Materials and Methods Ethical Approval}

The Institutional Review Board at King Fahad Medical City (KFMC) reviewed and approved the study (IRB number 19-539).

\section{Human Subjects and Sample Preparation}

Five to ten milliliters of blood was collected from 4 patients (median age of $53 \mathrm{y}$ ) admitted to KFMC with acute MERSCoV infection in 2019 (Table 1). MERS-CoV was detected using the RealStar ${ }^{\circledR}$ MERS-CoV RT-PCR Kit 1.0 (RT-PCR duplex assay) using an ABI Prism ${ }^{\circledR} 7500$ (Applied Biosystems). This independent assay targets the sequence upstream of the $\mathrm{E}$ gene (upE) and open reading frame region 1a (orfla) in the MERS-CoV genome. Information on symptom onset and medical history was obtained from each MERS-CoV-infected patient. The mean time from the onset of symptoms to hospital arrival seeking medical attention and hospital admission was 4.3 days. All samples were collected within one week of symptom onset (early phase of infection). All patients had flu-like symptoms,

Table I Demographic Data from the MERS-CoV-Infected Group and Healthy Noninfected Group (Collected in 20I9)

\begin{tabular}{|c|c|c|c|c|c|c|}
\hline Sample & Sex & $\begin{array}{c}\text { Age } \\
\text { (Median) }\end{array}$ & $\begin{array}{l}\text { Infection } \\
\text { Outcome }\end{array}$ & Specimen Type & $\begin{array}{c}\text { Detection of MERS- } \\
\text { CoV }\end{array}$ & $\begin{array}{c}\text { Detection of Other } \\
\text { Viruses }\end{array}$ \\
\hline $\begin{array}{l}\text { MERS-CoV-infected } \\
\text { group }\end{array}$ & & $(53.5 y)$ & & & & \\
\hline 1 & Female & 38 & Survived & Sputum/serum & + & - \\
\hline 2 & Female & 24 & Survived & Sputum/serum & + & - \\
\hline 3 & Male & 65 & Died & NPA/sputum/serum & + & - \\
\hline 4 & Male & 79 & Survived & Sputum/serum & + & - \\
\hline $\begin{array}{l}\text { Healthy noninfected } \\
\text { group }\end{array}$ & & $(35 \mathrm{y})$ & & & & \\
\hline 1 & Male & 23 & - & Sputum/serum & - & - \\
\hline 2 & Male & 45 & - & Sputum/serum & - & - \\
\hline 3 & Male & 28 & - & Sputum/serum & - & - \\
\hline 4 & Male & 49 & - & Sputum/serum & - & - \\
\hline 5 & Male & 35 & - & Sputum/serum & - & - \\
\hline
\end{tabular}

Abbreviations: NPA, nasopharyngeal aspirate, positive (+), negative (-). 
such as fever, chills, cough, and muscle pain. We included only MERS-CoV-infected patients without underlying chronic medical conditions to exclude any possible effects on the expression of clinicopathological factors. These patients were considered MERS-CoV-positive patients. Five healthy individuals (median age of $35 \mathrm{y}$ ) recruited from the blood bank as healthy volunteers comprised the MERS-CoV-noninfected group. Any patient who had a chronic disease or other acute or chronic infection or was undergoing antiviral treatment was excluded from the study. Individuals who are smokers or had received antibiotics or vaccines within the previous 2 weeks were also excluded. All patients in this study signed an "informed consent" form before sample collection in accordance with the Declaration of Helsinki. Serum was separated from blood and immediately kept at $-80^{\circ} \mathrm{C}$ for only the cytokine assessment. The samples were aliquoted, and freeze-thaw cycles were avoided.

\section{Cell Line}

Used in this research study, the A549 carcinoma airway epithelial cell line was purchased from ATCC (CCL-185). The cells were cultured in 25- $\mathrm{cm}^{2}$ flasks using Dulbecco's modified Eagle's medium (DMEM) supplemented with $10 \%$ fetal bovine serum (FBS), 4.5\% glucose, $3.7 \mathrm{~g} / \mathrm{L}$ sodium bicarbonate, and $2 \mathrm{mM}$ L-glutamine under 5\% $\mathrm{CO}_{2}$ at $37^{\circ} \mathrm{C}$. The cells were subcultured until the confluency reached $70-80 \%$.

\section{In vitro Stimulation with a Recombinant MERS-CoV Spike Protein}

A recombinant version of the full-length MERS-CoV spike protein (Sino Biological) was used at $5 \mu \mathrm{g} / \mathrm{mL}$ to stimulate the cells. In addition, cells were treated with anti-DPP4/CD26 antibody (R\&D Systems) for 1 hour (h) prior to stimulation with the recombinant protein to inhibit the receptor. The A549 cells were treated with or without anti-DPP4/CD26 antibody $(50 \mathrm{mmol} / \mathrm{mL})$ before stimulation with recombinant MERS-CoV full-length spike protein $(\mathrm{rSP})$ at $5 \mu \mathrm{g} / \mathrm{mL}$ for $24 \mathrm{~h}$. The culture supernatant was collected and stored at $-80^{\circ} \mathrm{C}$ for cytokine measurement.

\section{Bio-Plex Multiplex Assay}

This robust immunoassay facilitates the quantification of multiple protein biomarkers from a single sample in the single well of a 96-well plate in only 3-4 h using as little as $12.5 \mu \mathrm{L}$ of serum, as per the manufacturer's instructions (Bio-Plex Pro Human Inflammation Panel 1 (Bio-Rad, USA)). A magnetic bead assay was performed to analyze the levels of different cytokines/chemokines (IFN- $\alpha 2$, IFN- $\beta$, IFN- $\gamma$, IL- 2 , IL- 8, IL-10, IL-12p40, IL-12p70, IL26, IL-27 (p28) and IL-35). The concentration of each analyte bound to each specific set of beads was calculated based on a standard curve and is presented in $\mathrm{pg} / \mathrm{mL}$. Data from the reactions were acquired using a Bio-Plex threedimensional (3D) suspension array system. Bio-Plex Data Software (xPPONENT software v.4.2.1441.1) was used to quickly visualize the results and for simple statistical analysis. The lower and upper limits of quantification (LLOQ and ULOQ) were inputted from the standard curves included in the kit.

\section{Cytokine ELISA}

To measure the secretion of cytokines in the culture supernatant of the in vitro stimulated cells, we used multianalyte inflammatory cytokine ELISArray kits (Qiagen, Germantown, MD, USA). The levels of IL-2, IL-8, IL10 , IL-12 and IFN- $\gamma$, pro- and anti-inflammatory cytokines were simultaneously analyzed according to the manufacturer's instructions. Briefly, $50 \mu \mathrm{L}$ of the cell culture supernatant was added to the appropriate wells of the ELISArray plate, which included all specific cytokine/chemokine capture antibodies. After $2 \mathrm{~h}$ of incubation at room temperature (RT), the plate was washed, and $100 \mu \mathrm{L}$ of detection antibody was added to the appropriate wells and incubated for $1 \mathrm{~h}$ at RT. Subsequently, $100 \mu \mathrm{L}$ of diluted avidin-horseradish peroxidase (HRP) was added to all wells and incubated at RT for $30 \mathrm{~h}$. After washing, 100 $\mu \mathrm{L}$ of the development solution was added to each well and incubated for 15 minutes at RT in the dark. Finally, $100 \mu \mathrm{L}$ of stop solution was added to each well, and the absorbance of the obtained products at $450 \mathrm{~nm}$ was measured. The cytokine/chemokine levels are expressed in $\mathrm{pg} / \mathrm{mL}$.

\section{Statistical Analysis}

Statistical analysis was performed using GraphPad Prism software (version 5, USA). All nonnormally distributed data in the in vivo experiment are presented as the median $\left(25^{\text {th }}\right.$ $75^{\text {th }}$ percentile). The Mann-Whitney $U$-test was performed for comparisons between two groups (MERS-CoV-infected patients vs the healthy noninfected group). All in vitro data were analyzed by paired Student's t-test (normally distributed data) to compare the unstimulated control (UC) cells and 
stimulated cells. The data are presented with the standard error of the mean (SEM) of 3 independent experiments. Multiple comparisons between different cytokine parameters were performed using one-way ANOVA. *A $P$-value of $<0.05$ was used to indicate statistical significance.

\section{Results}

\section{MERS-CoV Patients Vs the Healthy}

\section{Noninfected Group}

Nasopharyngeal aspirate (NPA) or sputum from the MERS$\mathrm{CoV}$ patients was used for diagnosis and confirmation of MERS-CoV infection in the hospital (Table 1). However, serum from HCs was used for cytokine detection, and all recruited volunteers were considered healthy. All MERSCoV-infected patients tested negative for other viruses, such as parainfluenza (A, B), influenza, other coronaviruses, human bocavirus, rhinovirus, metapneumovirus, adenovirus, and respiratory syncytial virus (RSV) (Table 1).

\section{MERS-CoV Infection Decreased the IFN Response}

All patients showed noticeable increases in the levels of IFN-I (IFN- $\alpha 2$ and IFN- $\beta$ ) and IFN-II (IFN- $\gamma$ ) compared to those in healthy noninfected individuals (Figure 1). IFN- $\alpha 2$ levels (Figure 1C) ranged from 27.2 to $1154 \mathrm{pg} / \mathrm{mL}$ and were 8 -fold higher than those in $\mathrm{HCs}(43.4 \mathrm{pg} / \mathrm{mL}$ vs 5.3 $\mathrm{pg} / \mathrm{mL}$ ). The concentration of IFN- $\beta$ (Figure 1B) in the infected individuals was also higher than that in the healthy individuals $(17.7 \mathrm{pg} / \mathrm{mL}$ vs $6.2 \mathrm{pg} / \mathrm{mL})$, but the level of IFN$\alpha 2$ was much lower and ranged from 12 to $95 \mathrm{pg} / \mathrm{mL}$. In addition, IFN- $\gamma$ (Figure 1A) was increased 4-fold in all patients $(43.4 \mathrm{pg} / \mathrm{mL}$ vs $9.7 \mathrm{pg} / \mathrm{mL})$. The $p$-value for all IFN levels in the MERS-CoV patients compared to the HCs indicated statistical significance $(* \mathrm{p}<0.05)$.

\section{MERS-CoV Infection Elicited Marked Increases in IL-8 (CXCL-8) and IL-2 but Not IL-I2}

The chemokine IL-8 is a neutrophil chemoattractant that induces the recruitment of other proinflammatory cells to the site of infection and their infiltration. All patients with MERS-CoV showed a noticeable increase in IL- 8 by approximately 14 -fold $\left(13.7 \mathrm{pg} / \mathrm{mL}\right.$ vs $\left.0 \mathrm{pg} / \mathrm{mL}^{*} \mathrm{p}<0.05\right)$ and in IL2 by 4 -fold $\left(11.2 \mathrm{pg} / \mathrm{mL}\right.$ vs $\left.2.9 \mathrm{pg} / \mathrm{mL} ;{ }^{*} \mathrm{p}<0.05\right)$ compared to the levels in HCs (Figure 2A and B). One patient showed a very high level of IL-8 $(180 \mathrm{pg} / \mathrm{mL})$. However, two HCs showed a low concentration of IL-8 $(8 \mathrm{pg} / \mathrm{mL})$.

The present study did not show a significant difference in IL-12 (IL-12p40 and IL-12p70) between MERS-CoV patients and HCs (Figure 2C and D).

\section{MERS-CoV Infection is Associated with Regulatory Cytokines (IL-27 P28) and (IL-35) but Not Proinflammatory Cytokines (IL-26)}

Our study showed a significant increase in the regulatory cytokinesIL-27 $(57.8 \mathrm{pg} / \mathrm{mL}$ vs $13.8 \mathrm{pg} / \mathrm{mL} ; * \mathrm{p}<0.05)$ and IL-35 (167.5 pg/mL vs $87.5 \mathrm{pg} / \mathrm{mL}$; * $\mathrm{p}<0.05$ ) (Figure $3 \mathrm{C}$ and D) in MERS-CoV-infected patients compared to the HCs. IL-
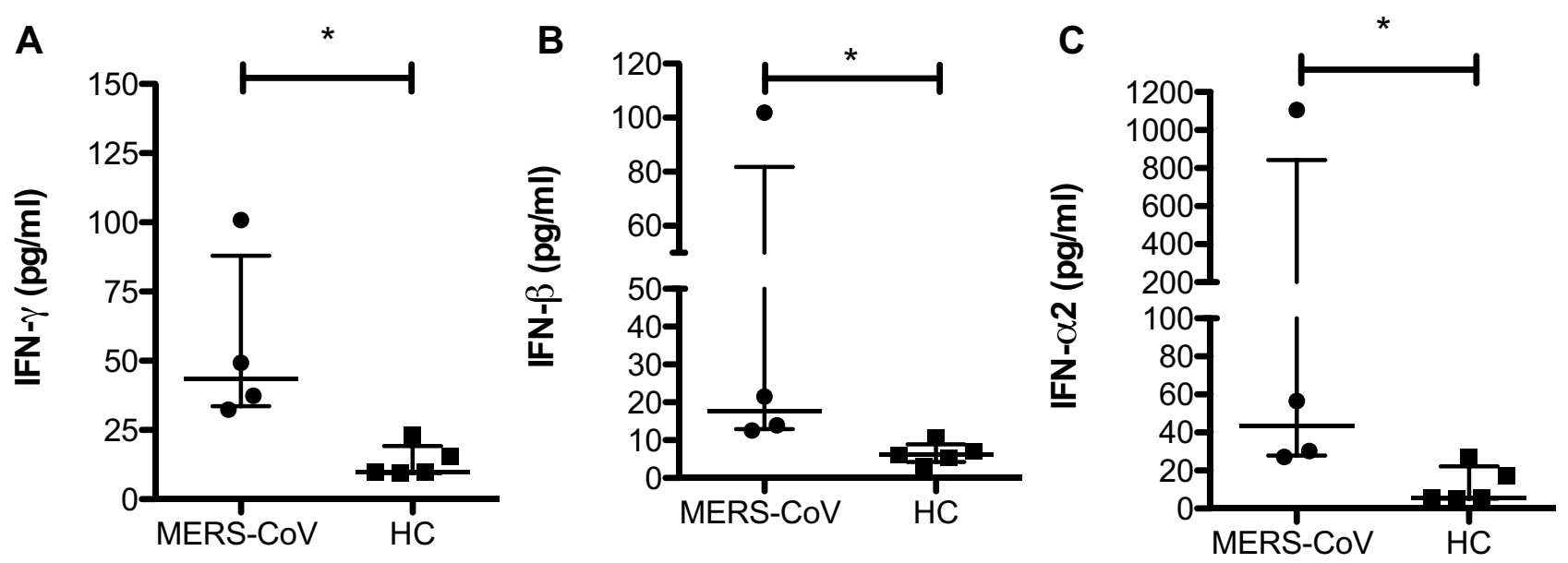

Figure I The level of IFNs in MERS-CoV-infected patients. Serum was assessed for expression of the IFNs IFN- $\gamma$ (A), IFN- $\beta$ (B) and IFN- $\alpha 2$ (C) in two different groups (MERS-CoV-infected patients vs the healthy noninfected group). All data are presented as the median $\left(25^{\text {th }}-75^{\text {th }}\right.$ percentile), and $* P$-value $<0.05$ indicates statistical significance.

Abbreviation: HC, healthy control. 


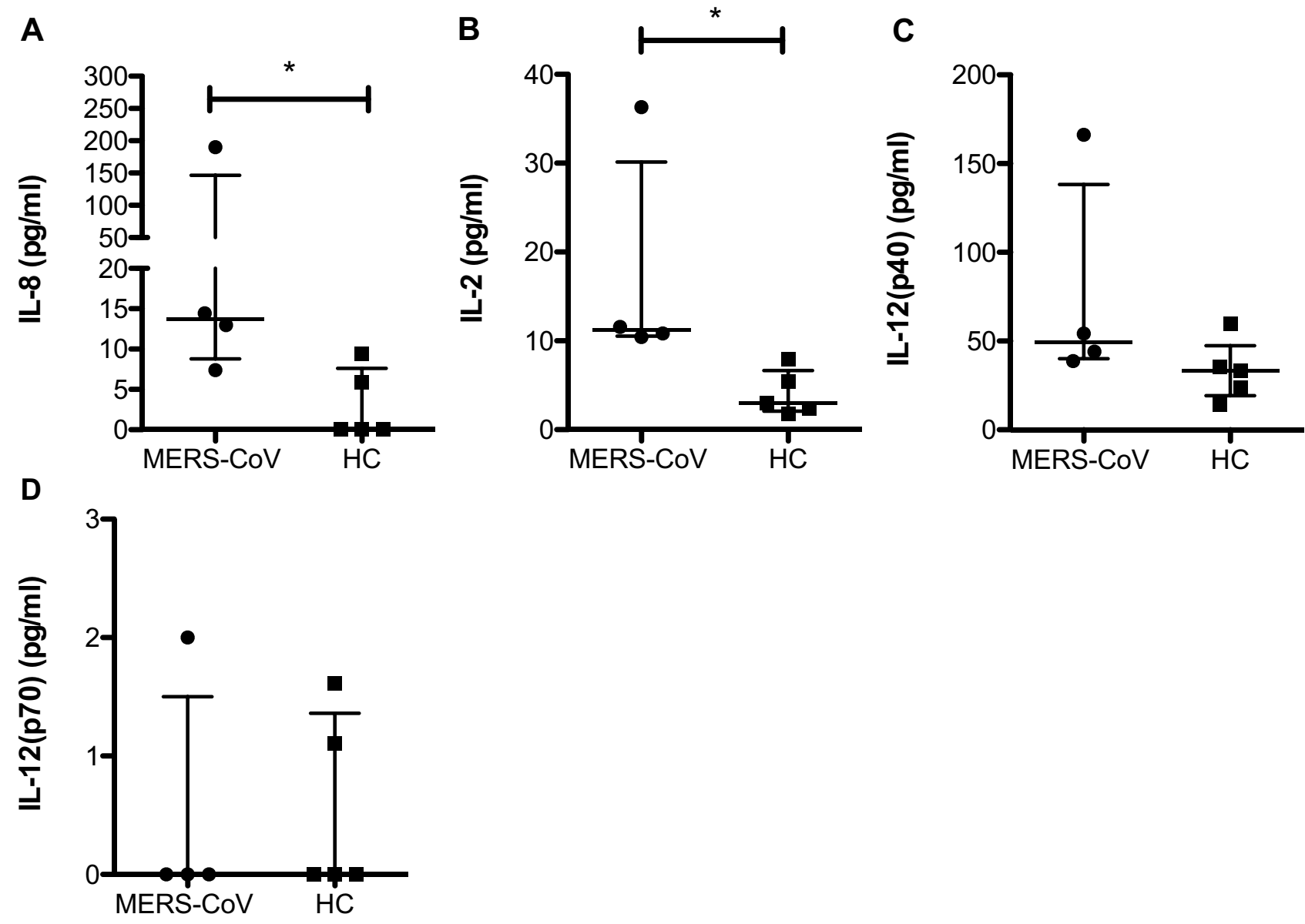

Figure 2 Differences in the concentrations of IL-8, IL-2, and IL-12 in MERS-CoV patients compared to the healthy noninfected group. Serum was assessed for the expression of IL-8 (A), IL-2 (B), IL-12p40 (C), and IL-I2p70 (D) in two different groups (MERS-CoV-infected patients vs healthy noninfected group as the control). All data are presented as the median $\left(25^{\text {th }}-75^{\text {th }}\right.$ percentile), and $* P$-value $<0.05$ indicates statistical significance.

Abbreviation: $\mathrm{HC}$, healthy control.

10, another anti-inflammatory cytokine, was slightly increased in patients infected with MERS-CoV relative to the HCs, but one patient showed a high level of IL-10 (28 pg/mL) (Figure $3 \mathrm{~B})$. In contrast, no difference in IL-26 between the two groups was found (32.5 pg/mL vs $50.3 \mathrm{pg} / \mathrm{mL}$ ) (Figure 3B). Compared to the HCs, one patient showed a higher level of IL$26(100 \mathrm{pg} / \mathrm{mL})$, and the other patients showed a lower level of IL-26 (Figure 3A). IL-27 was negatively correlated with IL-8, IFN- $\alpha 2$ and IFN- $\beta$. In addition, IL-35 was the most abundant cytokine in the MER-CoV-infected patient group (Figure 4).

\section{In vitro Stimulation of A549 Lung Cells with MERS-CoV rSP Increased the Levels of IL-8 and the ThI Cytokines IL-2 and IL-I 2}

The culture supernatants of A549 cells stimulated with MERS-CoV rSP (Figure 5A) showed higher levels of IL8 (155 pg/mL), IL-2 (102.6 pg/mL), and IL-12 (58 pg/mL) compared to those in the unstimulated control cells (18, 23 , and $0 \mathrm{pg} / \mathrm{mL}$, respectively). However, the levels of both IFN- $\gamma(129 \mathrm{pg} / \mathrm{mL})$ and IL-10 $(164 \mathrm{pg} / \mathrm{mL})$ in the culture supernatant were increased in the stimulated cells relative to the unstimulated control cells, but these levels were not remarkable. Treatment with anti-DPP4 antibody (Figure 5B) did not affect the levels of all cytokines, except for IL-8, the level of which was significantly decreased.

\section{Discussion}

Due to the emergence and reemergence of new coronaviruses, a good understanding of the immune response to MERS-CoV infection is needed. In this study, we sought to determine the levels of specific molecules related to the antiviral innate immune response and pro- and antiinflammatory cytokines in response to MERS-CoV infection. We analyzed different markers in serum samples 


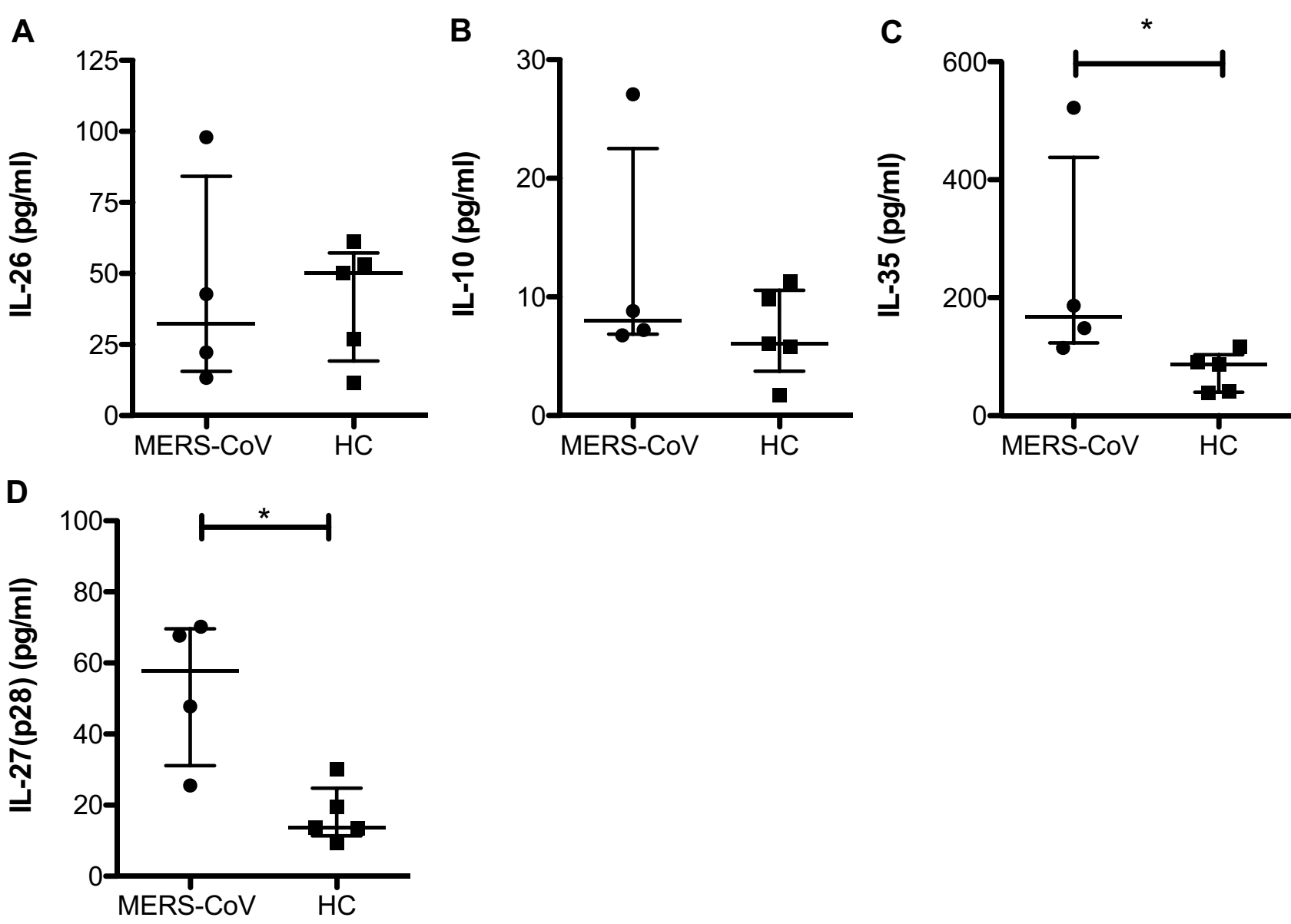

Figure 3 Levels of the cytokines IL-10, IL-26 and IL-35. Serum was assessed for the expression of IL-I0 (A), IL-26 (B), IL-35 (C), and IL-27 (D) in two different groups (MERS-CoV-infected patients vs the healthy noninfected group as the control). All data are presented as the median $\left(25^{\text {th }}-75^{\text {th }}\right.$ percentile), and $* P$-value $<0.05$ indicates statistical significance.

Abbreviation: $\mathrm{HC}$, healthy control.

from patients diagnosed with MERS-CoV infection. The levels of some cytokines/chemokines (IFNs, IL-2, IL-8, IL-27p28, and IL-35) were significantly increased in these patients compared to HCs. However, no significant difference in the concentrations of IL-12p40, IL-12p70, IL-10 or IL-26 upon comparison with the HCs was shown. These findings demonstrate the antiviral innate response in response to MERS-CoV infection. All three different IFNs measured (IFN- $\alpha 2$, IFN- $\beta$, and IFN- $\gamma$ ) were elevated in the serum samples of patients during infection compared to HCs. Additionally, the production of IFNs was observed in A549 cells. Mehallawi et al demonstrated that MERS-CoV can induce increased IFN- $\alpha 2$ and IFN- $\gamma$ expression. ${ }^{9}$ Type-I IFNs (IFN- $\alpha 2$, IFN- $\beta$ ) are important cytokines in the first line of defense against MERS-CoV infection. ${ }^{10}$ The levels of these antiviral factors were found to be relatively high compared to those in the HCs, which suggests that high IFN levels depend on disease severity.
The inhibition of IFN-I signaling is associated with a delay in viral clearance, an increase in neutrophils, and an impaired response to MERS-CoV. ${ }^{10}$ Furthermore, the expression of IFN-I was shown to be inhibited by the membrane (M) protein of MERS-CoV through interference with TANK-binding kinase 1 (TBK1)/IFN regulatory factor 3 (IRF-3) pathway activation. ${ }^{11}$ Moreover, various MERS-CoV proteins, such as accessory proteins (ORF 4a, ORF $4 b$ and ORF 5) and a papain-like protease, have shown a suppressive effect on the production of IFN-I. ${ }^{12}$ The accessory protein ORF 4a is an effective suppressor of retinoic acid-inducible gene I (RIG-I) and melanoma differentiation-associated protein 5 (MDA5), the suppression of which leads to impairment of the innate immune response to MERS-CoV. ${ }^{13}$ Most recently, SARS-CoV-2 infection was shown to be associated with cytokine storm and the dysregulation of innate immunity. ${ }^{14}$ Thus, the overall outcomes of the immune response to SARS- 

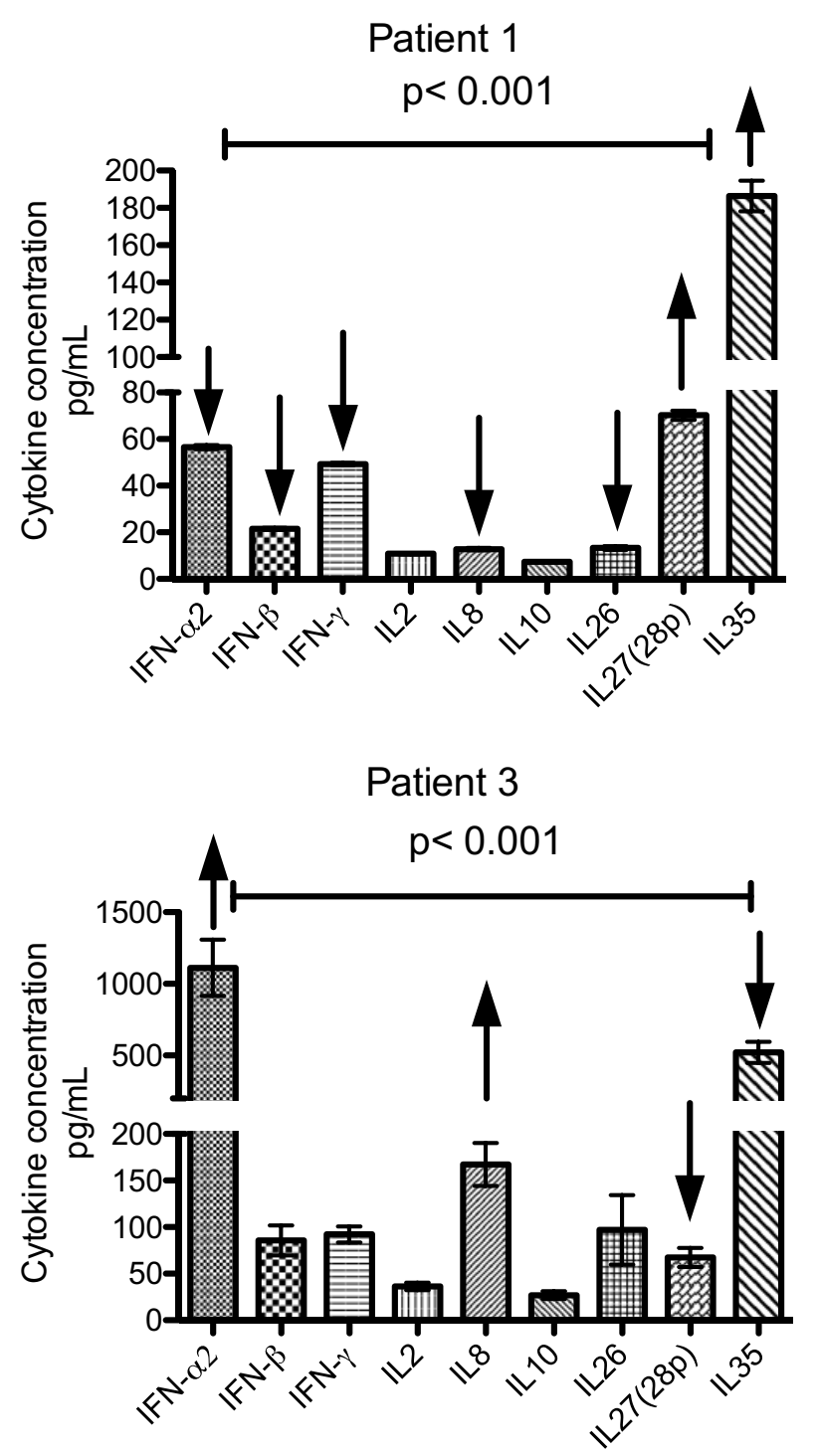
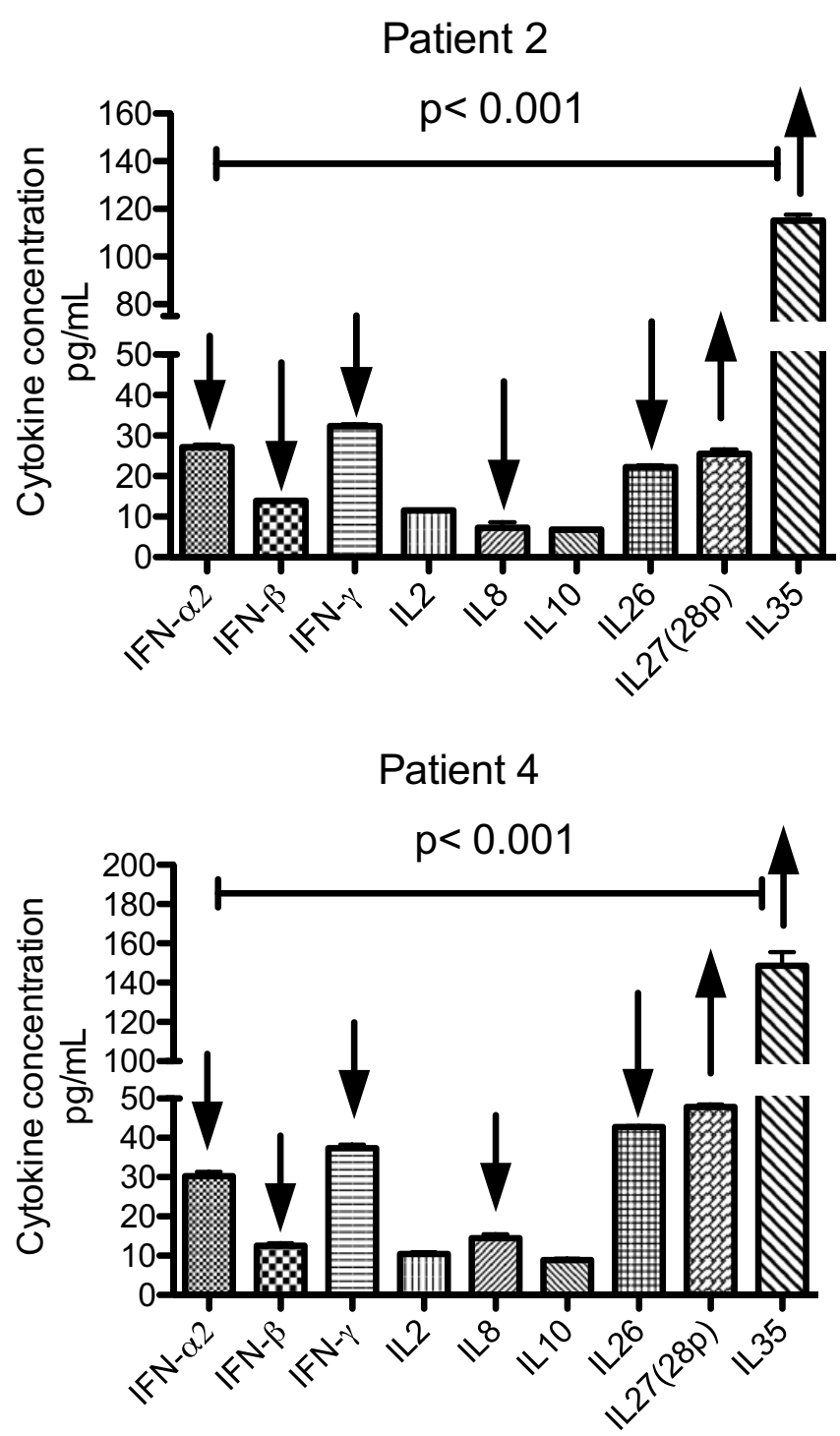

Figure 4 Effects of IL-27 (p28) on IL-8, IFN- $\alpha 2$ and IFN-B in 4 different patients. Serum samples were used for cytokine measurements by Bio-Plex multiplex assay. The data analysis was performed in duplicate for each patient sample, and data are presented as the mean (SEM). Comparison of the different cytokine levels was performed using one-way ANOVA. A $P$-value of $<0.001$ indicates statistical significance.

CoV-1, SARS-CoV-2 and MERS-CoV infection show similar patterns of innate immune induction.

After in vitro infection with MERS-CoV, the production of IFN- $\alpha / \beta$ was significantly increased in specific human plasmacytoid dendritic cells (pDCs), but not macrophages. ${ }^{15}$ Furthermore, IFN- $\beta$ was found to increase after the recognition of pathogen-associated molecular patterns (PAMPs) by cytosolic pattern recognition receptors (PRRs), such as MDA-5 or RIG-I, ${ }^{16}$ and IFN- $\alpha$ was increased after the interaction of MERS-CoV with endosomal PRRs in pDCs, such as Toll-like receptor-7 (TLR-7). ${ }^{17,18}$ The level of IFN- $\beta$ was decreased when MERS-CoV was inactivated by UV irradiation, which damaged the viral RNA, but the same amount of IFN- $\alpha$ was secreted. ${ }^{15}$
IL-8 (CXCL8) is an important chemokine during viral infection involved in the recruitment of other proinflammatory cells, such as monocytes and neutrophils. The accumulation of these cells at sites of infection leads to cytokine storm and induces toxicity in host cells, inflammation and tissue injury, thus worsening the immunopathology of the disease. ${ }^{19}$ Our study and those of others $^{9,19}$ are consistent as they all showed increased level of IL-8 (Figure 2A), but the concentrations of IL-8 measured in these studies are varied due to the type of samples examined and difference in infection severity. IL8 was also shown to increased upon SARS-CoV and RSV infection and associated with acute infection, immunopathology and disease enhancement during SARS and 
A
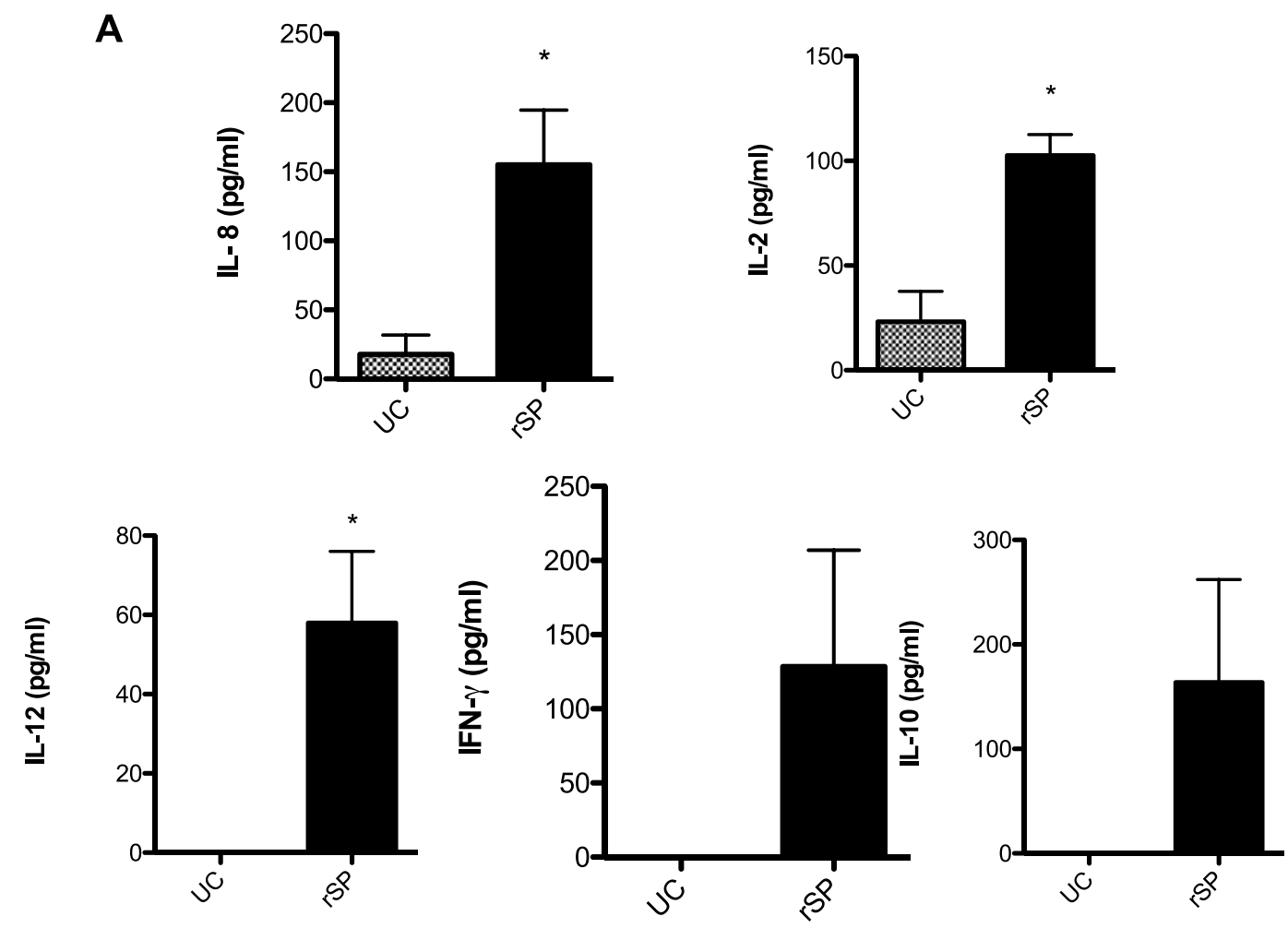

B
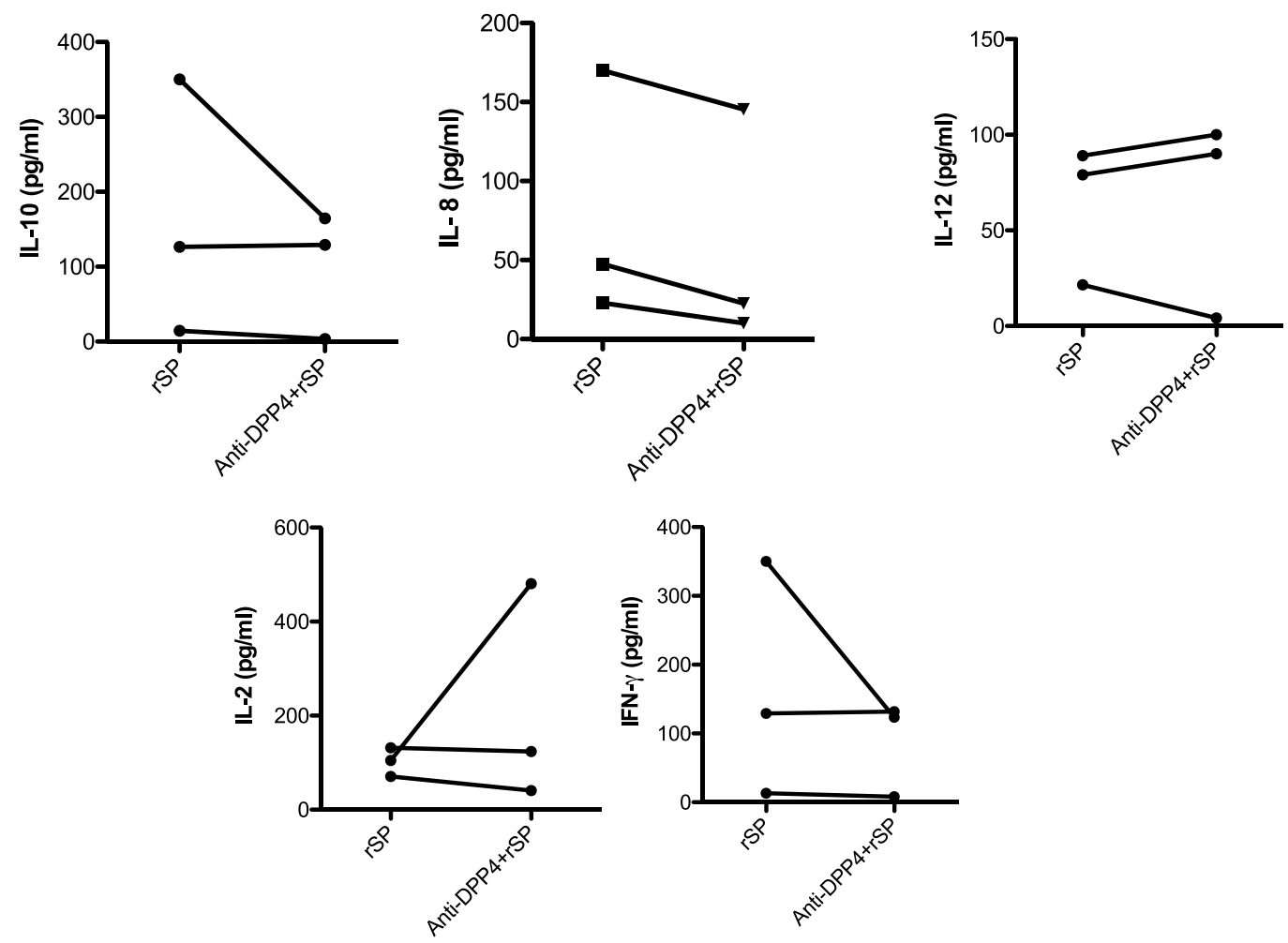

Figure 5 Levels of cytokines with or without treatment. A549 cells were stimulated with $\mathrm{rSP}(5 \mu \mathrm{g} / \mathrm{mL})$ alone $(\mathbf{A})$ or treated with anti-DPP4 (B) at $50 \mu \mathrm{M} / \mathrm{mL}$ for I h, stimulated with rSP at $5 \mu \mathrm{g} / \mathrm{mL}$ and then incubated for $24 \mathrm{~h}$. The paired Student's t-test was performed for comparisons between the two different groups. All data are presented with the standard error of the mean (SEM) from 3 independent experiments. $* P$-value $<0.05$ indicates statistical significance. Abbreviations: UC, unstimulated control; rSP, recombinant spike protein; anti-DPP4, anti-dipeptidyl peptidase 4. 
RSV infection. ${ }^{20-22}$ In vitro stimulation of the A549 cell line with MERS-CoV rSP induced a significant increase in IL- 8 and the Th1 cytokines IL-2 and IL-12. In addition, rSP triggered a noticeable increase in the secretion of IL10 (a Th2 cytokine) and IFN- $\gamma$ (Figure 5A). When cells were treated with anti-DPP4 antibody as an inhibitor protein, the production of IL-8 was remarkably reduced, but the treatment did not affect the other cytokines (Figure 5B). Thus, we can conclude that the use of this inhibitor is an inappropriate tool for reducing proinflammatory cytokines since the MERS-CoV spike protein can interact with other receptors on epithelial cells, such as TLR-4 or TLR-3.

Our work demonstrated that concentrations of the Th1 cytokines IL-2 and IFN- $\gamma$ were comparable between the MERS-CoV-infected group and HCs. This report is in agreement with that of another research group. ${ }^{9}$ However, though the level of IL-12 was not significantly increased in the infected group, it was considered high. IL12 is involved in the activation of $\mathrm{T}$ cells into CD4+ Th1 cells or CD8+ $\mathrm{T}$ cells and natural killer (NK) cells. This might be due to the induction of other regulatory cytokines, such as IL-35 and IL-27, during MERS-CoV infection, as demonstrated in this study, or because MERS-CoV infection skews the immune response to a Th2 response rather than a Th1 response and the secretion of an increased level of IL-10 and other cytokines, such as IL4, IL-5 and IL-13, in symptomatic patients. ${ }^{23}$

IL-10 is associated with the Th2 immune response, which is responsible for regulating and inhibiting the secretion of IFN- $\gamma$ and other proinflammatory cytokines. ${ }^{24}$ The increase in IL-10, a regulatory cytokine, has a negative impact on the innate immune response in the early stage of SARS-CoV infection. ${ }^{25}$ Thus, higher IL10 production is associated with lower IFN- $\gamma$ secretion from induced cells and higher IL-17 production, ${ }^{26}$ which was observed by another research group. ${ }^{9}$ Other studies have reported that IL-10 is significantly associated with MERS-CoV infection, leading to the persistence of viral infection. ${ }^{9,26}$ We found that the serum IL-10 concentration was higher in MERS-CoV-infected patients than in the noninfected individuals (Figure 3B). However, the level of IL-10 was high in one patient, which could delay clearance of the virus and worsen the condition of the patient. This might be attributed to infection severity. After viral clearance, the proportion of IL-10 gradually decreased to the normal level in HCs.
The secretion of IL-26 was assessed in MERS-CoVinfected patients, and we found no increase in IL-26 in serum samples from these patients (Figure 3A). However, one study reported that MERS-CoV and SARS-CoV increase the levels of IL-17 and IL-23 in the lung and BAL fluid early in infection. ${ }^{26}$ IL-23 in turn triggers the secretion of IL-17 in response to the virus. ${ }^{27} \mathrm{An}$ in vitro microarray analysis showed that IL-17A high upon infection with MERS-CoV compared to SAR-CoV. ${ }^{28}$

We have reported for the first time that both IL-35 and IL-27 were induced and that their expression was increased 3-fold in MERS-CoV infection compared to their expression in the HCs (Figure $3 \mathrm{C}$ and D). IL-27 is a proinflammatory cytokine that increases IFN- $\gamma$ via IL-12 and triggers activation of the transcription factor T-bet, which then mediates Th1 differentiation. However, IL-27 has direct and indirect inhibitory effects through its suppression of proinflammatory cytokines and different $\mathrm{T}$ cell subsets (CD4+ cells, Th17 cells and Foxp3+ Treg cells) or an increase in the production of IL-10, respectively. ${ }^{29-31}$

In addition, the increased production of IL-27 and IL35 might have affected the induction of IL- 8 , IFN- $\alpha$ and IFN- $\beta$ in patients 1,2 and 4 (Figure 4). In contrast, patient 3 showed low IL-27 secretion and uncontrolled, high levels of IL-8, IFN- $\alpha$ and IFN- $\beta$ (Figure 4). The effects on IL-27 differed between patient 2 and the other patients, but the effects on IL-35 were similar. Treatment with IL27 in a murine model of influenza with a high viral load led to improved lung pathology, reduced leucocyte influx and enhanced survival of the animal. Administration of IL-27 at an early stage of acute viral infection abrogated viral clearance and increased tissue damage. ${ }^{32}$ IL-35 was shown to suppress the specific differentiation of Treg cells into Th17-like cells in hepatitis B virus (HBV) infection by reducing IL-17 and IL-22 and inhibiting the expression of CCR4 and CCR6. Therefore, a large proportion of Treg cells and small proportion of Th17 cells were observed. A reduction or imbalance in the ratio of Treg/Th17 cells contributes to the persistence of HBV infection in chronic HBV patients. ${ }^{33}$ However, an ex vivo study of peripheral blood mononuclear cells (PBMCs) stimulated with HBsAg and IL-35 showed a reduction in the production of IL-1B, IFN- $\gamma$, IL- 6 and IL- 8 on one hand and an increase in the secretion of IL-10 on the other hand. ${ }^{34}$ Our results indicate that both IL-35 and IL-27 might play roles in the regulation of immune cell responses and cytokine secretion and contribute to the persistence of MERS-CoV. 
In conclusion, both IL-35 and IL-27 might play a role in the regulation of immune cell responses and cytokine secretion and contribute to the persistence of MERS-CoV. Thus, IL-27 and IL-35 can be regarded as novel biomarkers and targets for manipulation of the immune system. Targeting IL27 and IL-35 in the early stage of MERS-CoV infection might improve the immune response. However, the pleiotropic functions of IL-27 in regulating immune responses should factor into the design of therapeutics in the future. In contrast, targeting the DDP4 receptor did not have a therapeutic effect as it was unable to control the proinflammatory response during infection.

\section{Study Limitations}

The low number of samples taken from MERS-CoVinfected patients because sample collection occurred during the COVID-19 pandemic is the main concern related to this study. In addition, there were no reports of MERS$\mathrm{CoV}$ infection at that time. Increasing the sample size will improve the reliability of this study. Future in vitro and ex vivo studies will be conducted to determine the effects of IL-27 and IL-35 on the secretion of proinflammatory cytokines and proportions of CD4+ and CD8+ T cells.

\section{Acknowledgments}

The authors would like to thank the Research Center at King Fahad Medical City for funding this study (grant No. 020-014). We also thank Majmaah University, King Saud University, the Deanship of Scientific Research, and the College of Science Research Center for their support.

\section{Author Contributions}

All authors made substantial contributions to conception and design, acquisition of data, or analysis and interpretation of data; took part in drafting the article or revising it critically for important intellectual content; agreed to submit to the current journal; gave final approval of the version to be published; and agree to be accountable for all aspects of the work.

\section{Disclosure}

The authors have nothing to declare with respect to the research, authorship, and/or publication of this article.

\section{References}

1. Al-Qahtani AA, Lyroni K, Aznaourova M, et al. Middle east respiratory syndrome corona virus spike glycoprotein suppresses macrophage responses via DPP4-mediated induction of IRAK-M and PPAR $\gamma$. Oncotarget. 2017;8(6):9053-9066. doi:10.18632/oncotarget.14754
2. Mubarak A, Alturaiki W, Hemida MG. Middle East Respiratory Syndrome Coronavirus (MERS-CoV): infection, Immunological Response, and Vaccine Development. J Immunol Res. 2019;2019:6491738. doi:10.1155/2019/6491738

3. Zaki AM, van Boheemen S, Bestebroer TM, et al. Isolation of a novel coronavirus from a man with pneumonia in Saudi Arabia. $N$ Engl $J$ Med. 2012;367(19):1814-1820. doi:10.1056/NEJMoa1211721

4. Katze MG, He Y, Gale M. Viruses and interferon: a fight for supremacy. Nat Rev Immunol. 2002;2(9):675-687. doi:10.1038/ nri888

5. Yang Y, Zhang L, Geng H, et al. The structural and accessory proteins M, ORF 4a, ORF 4b, and ORF 5 of Middle East respiratory syndrome coronavirus (MERS-CoV) are potent interferon antagonists. Protein Cell. 2013;4(12):951-961. doi:10.1007/s13238013-3096-8

6. Alexopoulou L. Recognition of double-stranded RNA and activation of NF- $\mathrm{kB}$ by Toll-like receptor 3. Nature. 2001;413(6857):732-738.

7. Takeuchi O, Akira S. MDA5/RIG-I and virus recognition. Curr Opin Immunol. 2008;20(1):17-22. doi:10.1016/j.coi.2008.01.002

8. Yoneyama M, Kikuchi M, Natsukawa T, et al. The RNA helicase RIG-I has an essential function in double-stranded RNA-induced innate antiviral responses. Nat Immunol. 2004;5(7):730-737. doi:10.1038/ni1087

9. Mahallawi WH, Khabour OF, Zhang Q, et al. MERS-CoV infection in humans is associated with a pro-inflammatory Th1 and Th17 cytokine profile. Cytokine. 2018;104:8-13. doi:10.1016/j. cyto.2018.01.025

10. Channappanavar R, Fehr AR, Zheng J, et al. IFN-I response timing relative to virus replication determines MERS coronavirus infection outcomes. J Clin Invest. 2019;129(9):3625-3639. doi:10.1172/ JCI126363

11. Lui PY, Wong L-YR, Fung C-L, et al. Middle East respiratory syndrome coronavirus $\mathrm{M}$ protein suppresses type I interferon expression through the inhibition of TBK1-dependent phosphorylation of IRF3. Emerg Microbes Infect. 2016;5(1):e39. doi:10.1038/ emi.2016.33

12. Yang Y, Zhang L, Geng H, et al. The structural and accessory proteins $\mathrm{M}, \mathrm{ORF} 4 \mathrm{a}, \mathrm{ORF} 4 \mathrm{~b}$, and ORF 5 of Middle East respiratory syndrome coronavirus (MERS-CoV) are potent interferon antagonists. Protein Cell. 2013;4(12):951-961.

13. Siu K-L, Yeung ML, Kok K-H, et al. Middle East Respiratory Syndrome Coronavirus 4a Protein Is a Double-Stranded RNA-Binding Protein That Suppresses PACT-Induced Activation of RIG-I and MDA5 in the Innate Antiviral Response. $J$ Virol. 2014;88 (9):4866-4876. doi:10.1128/JVI.03649-13

14. Costela-Ruiz VJ, Illescas-Montes R, Puerta-Puerta JM, et al. SARSCoV-2 infection: the role of cytokines in COVID-19 disease. Cytokine Growth Factor Rev. 2020;54:62-75. doi:10.1016/j. cytogfr.2020.06.001

15. Scheuplein VA, Seifried J, Malczyk AH, et al. High secretion of interferons by human plasmacytoid dendritic cells upon recognition of Middle East respiratory syndrome coronavirus. J Virol. 2015;89 (7):3859-3869. doi:10.1128/JVI.03607-14

16. Li J, Liu Y, Zhang X. Murine coronavirus induces type I interferon in oligodendrocytes through recognition by RIG-I and MDA5. J Virol. 2010;84(13):6472-6482. doi:10.1128/JVI.00016-10

17. Birmachu W, Gleason RM, Bulbulian BJ, et al. Transcriptional networks in plasmacytoid dendritic cells stimulated with synthetic TLR 7 agonists. BMC Immunol. 2007;8(1):26. doi:10.1186/14712172-8-26

18. Coccia EM, Severa M, Giacomini E, et al. Viral infection and Toll-like receptor agonists induce a differential expression of type I and lambda interferons in human plasmacytoid and monocyte-derived dendritic cells. Eur J Immunol. 2004;34 (3):796-805. doi:10.1002/eji.200324610 
19. Alosaimi B, Hamed ME, Naeem A, et al. MERS-CoV infection is associated with downregulation of genes encoding Th1 and Th2 cytokines/chemokines and elevated inflammatory innate immune response in the lower respiratory tract. Cytokine. 2020;126:154895. doi:10.1016/j.cyto.2019.154895

20. Zhang Y, Li J, Zhan Y, et al. Analysis of serum cytokines in patients with severe acute respiratory syndrome. Infect Immun. 2004;72 (8):4410-4415. doi:10.1128/IAI.72.8.4410-4415.2004

21. Wong CK, Lam CWK, Wu AKL, et al. Plasma inflammatory cytokines and chemokines in severe acute respiratory syndrome. Clin Exp Immunol. 2004;136(1):95-103. doi:10.1111/j.1365-2249.2004.02415.x

22. Mella C, Suarez-Arrabal MC, Lopez S, et al. Innate immune dysfunction is associated with enhanced disease severity in infants with severe respiratory syncytial virus bronchiolitis. J Infect Dis. 2013;207 (4):564-573. doi:10.1093/infdis/jis721

23. Alhetheel A, Albarrag A, Shakoor Z, et al. Assessment of Th1/Th2 cytokines among patients with Middle East respiratory syndrome coronavirus infection. Int Immunol. 2020;32(12):799-804. doi:10.1093/intimm/dxaa047

24. Sabat R. IL-10 family of cytokines. Cytokine Growth Factor Rev. 2010;21(5):315-324. doi:10.1016/j.cytogfr.2010.11.001

25. Perlman S, Netland J. Coronaviruses post-SARS: update on replication and pathogenesis. Nat Rev Microbiol. 2009;7(6):439-450. doi: $10.1038 /$ nrmicro2147

26. Faure E, Poissy J, Goffard A, et al. Distinct immune response in two MERS-CoV-infected patients: can we go from bench to bedside? PLoS One. 2014;9(2):e88716. doi:10.1371/journal.pone.0088716

27. Wang Q, Zhou J, Zhang B, et al. Hepatitis B virus induces IL-23 production in antigen presenting cells and causes liver damage via the IL-23/IL-17 axis. PLoS Pathog. 2013;9(6):e1003410. doi:10.1371/ journal.ppat.1003410
28. Josset L, Menachery VD, Gralinski LE, et al. Cell host response to infection with novel human coronavirus EMC predicts potential antivirals and important differences with SARS coronavirus. mBio. 2013;4(3):e00165-13. doi:10.1128/mBio.00165-13

29. Stumhofer JS, Laurence A, Wilson EH, et al. Interleukin 27 negatively regulates the development of interleukin 17-producing $\mathrm{T}$ helper cells during chronic inflammation of the central nervous system. Nat Immunol. 2006;7(9):937-945. doi:10.1038/ni1376

30. Stumhofer JS, Silver JS, Laurence A, et al. Interleukins 27 and 6 induce STAT3-mediated $\mathrm{T}$ cell production of interleukin 10. Nat Immunol. 2007;8(12):1363-1371. doi:10.1038/ni1537

31. Povroznik JM, Robinson CM. IL-27 regulation of innate immunity and control of microbial growth. Future Sci OA. 2020;6(7):FSO588. doi:10.2144/fsoa-2020-0032

32. Liu FDM, Kenngott EE, Schröter MF, et al. Timed action of IL-27 protects from immunopathology while preserving defense in influenza. PLoS Pathog. 2014;10(5):e1004110. doi:10.1371/journal. ppat. 1004110

33. Yang L. Interleukin-35 modulates the balance between viral specific CD4(+)CD25(+)CD127(dim/-) regulatory $\mathrm{T}$ cells and $\mathrm{T}$ helper 17 cells in chronic hepatitis B virus infection. Virol J. 2019;16(1):48. doi:10.1186/s12985-019-1158-0

34. Shao X, Ma J, Jia S, et al. Interleukin-35 Suppresses Antiviral Immune Response in Chronic Hepatitis B Virus Infection. Front Cell Infect Microbiol. 2017;7:472. doi:10.3389/fcimb.2017.00472
Journal of Inflammation Research

\section{Publish your work in this journal}

The Journal of Inflammation Research is an international, peerreviewed open-access journal that welcomes laboratory and clinical findings on the molecular basis, cell biology and pharmacology of inflammation including original research, reviews, symposium reports, hypothesis formation and commentaries on: acute/chronic inflammation; mediators of inflammation; cellular processes; molecular mechanisms; pharmacology and novel anti-inflammatory drugs; clinical conditions involving inflammation. The manuscript management system is completely online and includes a very quick and fair peerreview system. Visit http://www.dovepress.com/testimonials.php to read real quotes from published authors. 